\title{
Applications of Quantitative Techniques in Decision Making of Business Organisation
}

\author{
Dr. A. Malleswari Devi', Mrs. A. Devaki² \\ ${ }^{1}$ Associate Professor in Commerce, ${ }^{2}$ Lecturer in Commerce \\ ${ }^{1}$ S. P. W. Degree \& P. G. College, Tirupati, Andhra Pradesh, India \\ ${ }^{2}$ Government Degree College, Nagari, Andhra Pradesh, India
}

\begin{abstract}
How to cite this paper: Dr. A. Malleswari Devi | Mrs. A. Devaki "Applications of Quantitative Techniques in Decision Making of Business Organisation" Published in International Journal of Trend in Scientific Research and Development (ijtsrd), ISSN: 24566470, Volume-3 | Issue-3, April 2019, pp.568-571, URL: http://www.ijtsrd.co $\mathrm{m} /$ papers/ijtsrd228 89.pdf

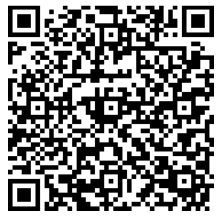

IITSRD22889
\end{abstract}

Copyright (C) 2019 by author(s) and International Journal of Trend in Scientific Research and Development Journal. This is an Open Access article distributed under the terms of the Creative Commons

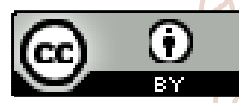
Attribution License (CC BY 4.0) (http://creativecommons.org/licenses/ by/4.0)

\section{INTRODUCTION}

In the business world, and in fact, in practically every aspect of daily living, quantitative techniques are used to assist in decision making. Quantitative techniques are used to assist in decision making. managers must be able to use quantitative techniques in a confident and reliable manner.

A small business owner is always making decisions under uncertainty. In the world of business, nothing is ever done with total confidence that you have made the right decision. Fortunately, numerous quantitative techniques are available to help organize and assess the risks of various issues.

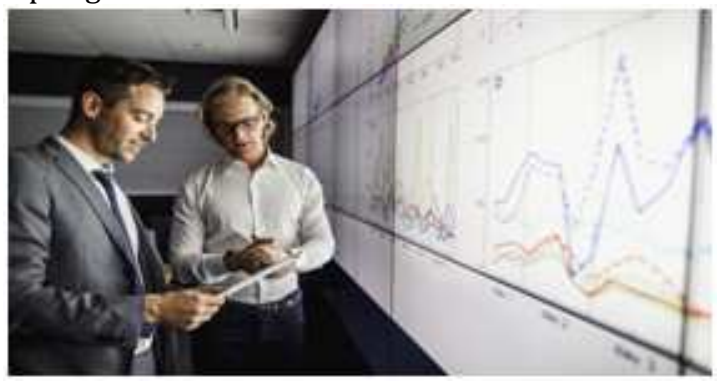

Management science (MS) is an interdisciplinary branch of applied mathematics devoted to optimal decision planning with strong links with economics, business, engineering and other sciences. It uses various scientific research-based principles, strategies and analytical methods including mathematical modelling, statistics and numerical algorithms to improve an organisation's ability to enact rational and meaningful management decisions by arriving at optimal or near optimal solutions to complex decision problems. In short, management sciences help businesses to achieve their goals using the scientific methods of operational research. Management science is concerned with developing and applying models and concepts that may prove useful in helping to elucidate management issues and solve managerial problems, as well as designing and developing new and better models of organisational excellence. The application of these models within the corporate sector became known as management science. The problem solving process involves the following seven steps:

1. Identify and define the problem

2. Determine the set of alternative solutions

3. Determine the criteria to evaluate the alternatives

4. Evaluate the alternatives

5. Choose an alternative

6. Implement the selected alternative

7. Evaluate the results. 
Quantitative models give managers a better grasp of the problems so that they can make the best decisions based on the information available. Quantitative techniques are used by managers in practically all aspects of a business.

\section{Project Management}

Quantitative methods have found wide applications in project management. These techniques are used for optimizing the allocation of manpower, machines, materials, money and time. Projects are scheduled with quantitative methods and synchronized with delivery of material and workforce.

\section{Production Planning and Scheduling}

Determining the size and location of new production facilities is a complex issue. Quantitative techniques aid in evaluating multiple proposals for costs, timing, location and availability of transportation. Product mix and scheduling get analysed to meet customer demands and maximize profits.

\section{Purchasing and Inventory}

Predicting the amount of demand for a product is always risky and uncertain. Quantitative techniques offer guidance on how much raw material to purchase, levels of inventory to keep and costs to ship and store finished products.

\section{Marketing}

Marketing campaigns get evaluated with large amounts of data. Marketers apply quantitative methods to set budgets, allocate media purchases, adjust product mix and adapt to customers' preferences. Surveys produce data about viewers' responses to advertisements. How many people saw the ads, and how many purchased the products? Such information is evaluated to get the return on investment in an advertising campaign.

\section{Finance}

Financial managers rely heavily on quantitative techniques. They evaluate investments with discounted cash flow models and return on capital calculations. Products get analysed for profit contribution and cost of production. Workers are scrutinized for productivity standards and hiring or firing to meet changing workloads.

Predicting cash flow is always a critical concern for managers, and quantitative measurements help them to predict cash surpluses and shortfalls. They use probabilities and statistics to prepare annual profit plans.

\section{Research and Development}

Risking funds on research and development is always a bestguess scenario. The outcomes are never certain. So, managers look to mathematical projections about the probability of success and eventual profitability of products to make investment decisions.

\section{Agriculture}

Operations research techniques have long been employed by farmers. They utilize decision trees and make assumptions about weather forecasts to decide which crops to plant. If forecasters predict cold weather, is it more profitable to plant corn or wheat? What happens if the weather is warm? These are all probabilities that farmers use to plan their crop rotations.
A variety of quantitative methods of analysis are finding more applications in business as managers learn how to use these techniques to provide more insight into problems and aid in daily decision-making.

It is evident that quantitative techniques like mathematical and statistical models which are describing a diverse array of variables relationship, and they are designed to assist managers with management problem-solving and decision making. There are many of mathematical and statistical techniques which can be used to help decision making by managers of all types of business organization: large or small, private sector, public sector, profit-oriented, manufacturing, or service sector. Statistics is defined as the process of collecting a sample, organizing, analysing and interpreting data. The numeric values which represent the characteristics analysed in this process are also referred to as statistics.

In an increasingly complex business environment managers have to grapple with a problem and issues which range from the relatively trivial to the strategic. In such an environment the quantitative techniques have an important role. It is obvious that life for any manager in any organization is becoming increasingly difficult and complex.

Organizations find themselves operating in an increasingly complex environment. Changes in government policy, privatization, increasing involvement of the other country's union contribute to this complexity. At the same time, organizations face increasing competition from both home and abroad.

Because of the increasing complexity of the business environment in which organizations have to function, the information needs of a manager become more complex and demanding also. The time available to a manager to asses, analyse and react to a problem or opportunity is much reduced. Managers and their supporting information systems need to take fast, and hope-fully appropriate, decisions. Finally, to add to the problems, the consequences of taking wrong decisions become more serious and costly. Entering the wrong markets, producing the wrong products or providing inappropriate services will have major and big consequences for organizations.

Managers must learn what the various tools are designed to do and what the limits of their capabilities are. They must be able to understand what staff specialists are attempting to achieve by a particular analysis and to discuss the appropriateness of alternative procedures sensibly (which also requires the development of additional vocabulary). They must fully understand the variables a model will and will not consider and be able to evaluate whether the relationships among the variables are sensible. Managers cannot use an analytical tool wisely unless they fully comprehend the underlying assumptions, what the analysis achieves, what compromises the model makes with reality, and how its conclusions are to be adapted to changing circumstances and intangible considerations. All this process requires a more thorough knowledge of operations than of mathematics. 
The processing of real problems solving involves the following steps:

1. Identification of corporate environment and uncertain conditions

2. Existence of Independent Management Units

3. Integrated approach of actual situations

4. Implementation of Scientific Approach

Processing is primarily a matter of understanding that the new reality is exogenously given, irreversible and one-way pace. Open-minded cost/benefit analysis overcomes hesitation and postponement and produces synergy effects in due course, whereas the cost of inaction may be insuperably higher than the action now. Critical role has the timing for the problem of competitiveness in an uncertain environment, incorporating the probability distributions of the variables considered into the analysis. Decision-making under uncertainty conditions is an analytic framework of searching for:

1. Optimal strategies, as acts from all possible courses of action, choices under control of the decision maker.

2. Various possible outcomes, states of nature or events to be identified, beyond the control of the decision maker.

3. Determination of the pay-off function by describing different combinations of acts and events and the resulting consequences, the pay-off resulting from the $\mathrm{i}$ th strategy and the $\mathrm{j}$-th event. A pay-off is a conditional value - a conditional profit, loss or, may be, a conditional cost. In building up apay-off matrix, the alternative courses of action and the possible outcomes (events) must be clearly determined.

The trade-offs among decisions under uncertainty, within cost/benefit analysis, uses a number of basic principles, as parts of the decision matrix:

1. The Laplace Principle (highest mean value or lowest average cost), the Maxima or Minima Principle (choice of the maximum from a set of strategies with minimum pay-offs, adopted by pessimistic decision makers. While such a principle has the logic of ensuring that decision makers are in the best possible position if the worst happens, the principle does obviously ignore the potentially larger profit contributions that can be made by other decisions);

2. The Maxima or Minima Principle (choice of the maximum from strategies with the highest pay-offs, adopted by optimistic decision makers. In general, for this principle, decision makers determine the maximum pay-off for each decision and then choose the largest of these. This principle has the advantage of focusing on the best possible outcome.);

3. The Hurwitz Principle (choice somewhere between the extreme pessimism of the maxima and the extreme optimism of the maxima principle);

4. The Savage Principle (choice of action that minimizes the maximum opportunity losses from the so called regret table);

5. The Maximum Likelihood Principle (considering first the event that is most likely to occur and choice of the course of action which has the maximum conditional pay-off.);

6. The Bayesian Decision Rule (an extension of the optimal strategy choice by calculation of the expected pay-offs by using posterior probabilities, as additional information about events is acquired);
7. The Expectation Principle (the optimal choice represents the strategy with the highest expected payoffs, calculated by multiplying the pay-off values with their respective probabilities and adding up these products).

The choice in decision making under risk conditions depends on a series of objective and subjective factors, to mention a few: information, enough knowledge of technology possibilities, attitudes against risk, etc. Decision support systems, analytical information technology and decision trees are helpful in decision-making. The methods for creating and analysing models, incorporating multiple scenarios and more explicit treatment of uncertainty, involve two overlapping disciplines: stochastic programming and a relatively new field of strategy analysis called scenario planning.

The risks of errors in estimates and predictive power of the scientific methods are higher in phases of structural changes to adjust in an irreversible new world. Scientific methods aim at assisting the adjustment process that is a matter of philosophy and conceptual framework e.g. the management that serves the fundamental economic axiom, by eliminating the misconceptions and co-ordinating effective mobilization of total available resources.

Testing hypotheses leads to either confirmation or rejection of a hypothesis. Theories, which cannot be tested, because, they have no observable ramifications, do not qualify as scientific theories. If the predictions are found to be in disagreement with new experimental results, the theory may be discarded as a description to reality, but it may continue to be applicable within a limited range of measurable parameter.

\section{CONCLUSION}

Quantitative analysis concentrates on the facts, data, or quantitative aspects associated with problems. A managers educational and technical knowledge of quantitative procedures help to enhance the decision-making process. The manager who is knowledgeable in quantitative decisionmaking procedures is in a much better position to compare and evaluate the qualitative and quantitative sources of information, or ultimately, to combine alternatives to make the best possible decisions.

To an ever-increasing extent, modern management is adopting and applying quantitative techniques to aid in the process of decision making. The intelligent use of the appropriate tools can reduce an otherwise highly complex problem to one of manageable dimensions. Indeed, it is a fact that the greatest impact of the quantitative approach will not be in the area of problem solving, but will rather be on problem formulation. It will radically alter the way managers think about their problems-how they size them up, gain new insights, relate them to other problems, communicate with other people about them, and gather information for solving them. Thus quantitative analysis could have a profound effect on the "art" of management in taking decision effectively and efficiently for any business organisation in selecting the suitable alternative course of action or any project alternative. 
International Journal of Trend in Scientific Research and Development (IJTSRD) @ www.ijtsrd.com eISSN: 2456-6470

\section{REFERENCES}

[1] AMET Journal of Management Jan - June 2011.

[2] Columbia University: Introduction to Operations Research.

[3] Essay UK - http://www.essay.uk.com/free-essays/ management/role-in-quantitative-techniques-decisionmaking.php.
[4] Journal of Multidisciplinary Engineering Science \& Technology: Operational Research: A Study of Decision Making Process.

[5] Sharma \& Guptha, A text book of Quantitative Techniques (2009), Kalyani Publishers.

[6] University of Waterloo: Examples of Operations Research.

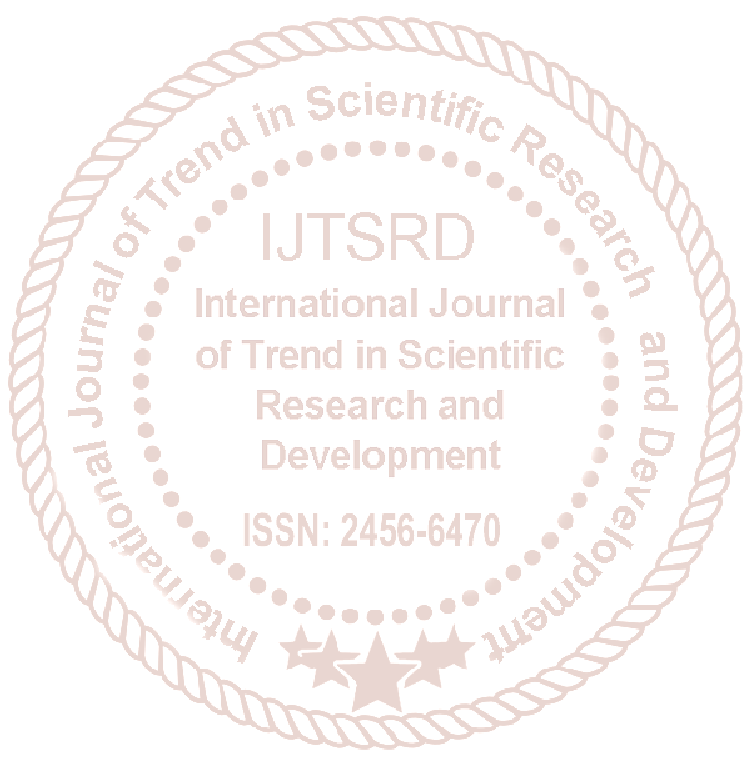

